\title{
Institutional accreditation by nursing education and training quality assurance: Perspectives of heads of private nursing institutions in South Africa
}

\author{
Ntombifikile Gloria Mtshali ${ }^{1}$, Thobile Shelembe ${ }^{1}$, Joanne Rachel Naidoo ${ }^{2}$, Alexis Harerimana*1 \\ ${ }^{1}$ University of KwaZulu-Natal, Durban, South Africa \\ ${ }^{2}$ Nelson Mandela University, Port Elizabeth, South Africa
}

Received: September 6, 2019

Accepted: September 22, 2019

Online Published: November 26, 2019

DOI: $10.5430 /$ jnep.v10n2p91

URL: https://doi.org/10.5430/jnep.v10n2p91

\begin{abstract}
Background and objective: Nursing education throughout the world is striving for international competitiveness and accountability for effectiveness, quality, and trust to the students, patients, and the community, thus making the issue of institutional accreditation increasingly important. The aim of this paper was to explore the perceptions of heads of private nursing institutions on the benefits of school accreditation by nursing education and training quality assurance (ETQA) in KwaZulu-Natal region, South Africa.

Methods: The study adopted a qualitative approach. Data were collected from seven heads of private nursing institutions. In-depth interviews were used to explore the perceived benefits of the accreditation of nursing institutions by Nursing ETQA. Thematic content analysis was used in this study to analyse the collected data. The study adhered to all ethical principles.

Results: The findings from this study revealed that heads of private nursing institutions perceived the accreditation by nursing ETQA as a tool used to promote quality outcomes in nursing education. Results from this study further revealed that accreditation is a mechanism of ensuring high standards of performance, and it increases trust, confidence, and reinforcement of uniformity across the nursing education sector. In this study, several challenges were reported to hinder the accreditation process including as a disjoint and an inconsistent process of accreditation, unclear criteria for accreditation, the high cost of accreditation, accreditation being detrimental to teaching the outcome, lack of uniformity in the recommendations; and a lengthy process of accreditation. Conclusions: Accreditation is an important tool to ensure that programs and degrees meet the highest standards of education. In nursing education, the accreditation process is associated with several challenges, and there is a need for collaborative and well-coordinated accreditation of nursing schools nationally and globally.
\end{abstract}

Key Words: Quality assurance, Education and training, Nursing Education, Standards of performance, Accreditation

\section{BACKGROUND}

Accreditation is becoming increasingly important in public and private sectors, particularly in education. In nursing education, accreditation is recognised as an evaluation process used to assess and improve the quality, efficiency, and effectiveness of education. ${ }^{[1]}$ According to Jones and Saram ${ }^{[2]}$ formalised accountability, specifically meaning accreditation, refers, in general, to a formal system of procedures that are instituted to ensure quality control of teaching and learning. There is abundant evidence available that indicates that changes in healthcare and transformation in nursing education are underpinned by relevant training and education, and

*Correspondence: Alexis Harerimana; Email: haralexis@yahoo.fr; Address: University of KwaZulu-Natal, Durban, South Africa. 
efficient accreditation process. ${ }^{[3,4]}$

Accreditation is based on the premise that adherence to evidence-based standards will produce higher quality nurses that will provide efficient patient care, in an increasingly safe environment. ${ }^{[5,6]}$ The quality gradients are embedded into the nursing education institutions accreditation process. ${ }^{[6]}$

Nicklin ${ }^{[1]}$ asserts that the accrediting body periodically or cyclically assesses the institution to measure the institutional performance against pre-established standards. Furthermore, accreditation is a way to publically recognise that a nursing education institution has met national quality standards. Furthermore, it serves as a risk mitigation strategy as it is used as a benchmark to measure performance. This performance measure contributes to the sustainability and ongoing quality provision in nursing education institution. ${ }^{[1,7]}$ In education and training of nurses, it is imperative to ensure that the training meets the standards, through an effective program accreditation. $^{[7]}$

Moore et al. ${ }^{[8]}$ point out that in Canada, the Donabedian nursing education quality model is seen as a valid model for evaluating quality nursing education. Improvement in the structure of nursing education leading to quality standards and improvements in the process should, in turn, improve student's competencies. Supporting this notion, Shaw et al. ${ }^{[9]}$ also pointed out that accreditation is widely used as tools for regulating quality and marketing learning programs offered in the nursing education institution. According to American Nurses Credentialing Centre, ${ }^{[10]}$ the three categories of criteria that should be taken into consideration in the accreditation include structural capacity, educational design principles, and quality outcomes such as those impacting on the professional practice of nursing, and patients or system. These criteria provide the framework within which accredited nursing education institutions design, implement, and evaluate quality nursing education activities.

In nursing education, activities are developed with the specific intent of meeting the learning needs of student nurses. Gaps are identified to indicate the difference between where learners currently are in their knowledge, skills, and/ or practice and where they need to be in order to achieve the desired outcomes. Needs assessment and gap analysis are used widely in both nursing education and clinical facilities to support and measure the quality in nursing education. ${ }^{[10]}$

The accreditation of nursing education institutions builds a culture of support, communication, and team-building that strengthens bonds with the organisation and promotes retention of qualified, committed nurse educators. ${ }^{[11]}$ Supporting this notion Teng et al. ${ }^{[12]}$ assert that nurse educators' com- mitment enhances nursing education quality; commitment includes factors of belief in nursing educations goals and values, willingness to make significant efforts to support, and a desire to remain loyal to nursing education institution, thus creating students' trust to the nursing education institution. Quality assurance and Accreditation encourage and assist nursing education institutions to review and upgrade their curricula with the goal of improving teaching and learning as well as bringing their curricular up to the national and international standards. ${ }^{[13,14]}$

\subsection{Context of the study}

In the context of South Africa, the Council of Higher Education, South African Qualification Authority (SAQA), South African Nursing Council (SANC), and the Department of Higher Education and Training provide the accreditation of the nursing institution. The SANC is empowered by Nursing Act, 2005 (Act No.33 of 2005), which makes it illegal for any institution in South Africa to provide education or training intended to qualify a person to practice as a nurse or a midwife unless both the institution and the program of education are approved by the Nursing ETQA (Education and Training Quality Assurance). ${ }^{[15]}$

The South African Qualifications Authority is in charge of the National Qualifications Framework (NQF), and its task is to register qualifications and standards on the NQF and to ensure that education and training programs help students to reach these qualifications and standards. ${ }^{[16]}$

The Department of Education is involved in maintaining the structures of the SAQA, and the NQF and neither the SAQA nor the NQF can exist without the foundation of the Department of Education. The Department of Education's function is set out by the SAQA Act (No. 58 of 1995) and the National Education Policy Act (Act 27 of 1996). The functions of the Department of Education are to create a single, unified system of education and training qualification and create the institutions to ensure that these qualifications are of high quality. ${ }^{[17]}$

The SAQA Act (Act No58 of 1998) tries to unify education and training. In the past, school leavers with Grade 12 could continue their education at universities. According to Bell and Young, ${ }^{[18]}$ the SAQA Act (No.58 of 1998) states that both education and training are recognized forms of learning and that both forms must share important characteristics if they are to be useful to people. The SAQA Act (No 58 of 1998) states that people must not be stuck on either side of an education-training device, but that they must be able to use the learning that they have acquired on one side to move forward on the other side. 
Teshome and Kobede ${ }^{[19]}$ maintain that although higher education institutions have embraced the concept of quality through accreditation, a number of quality-related problems still persist. Thobega ${ }^{[20]}$ asserts that accreditation of private institutions is an area where accrediting bodies continue to meet the most complex dilemmas. According to this author, there are cases where guidelines have not been compiled, and criteria and standards to describe present and desirable quality via the accreditation process are not in place. While external quality assurance systems should complement internal quality structures, more emphasis has been placed on the external evaluation of quality, while the internal quality assurance systems have been ignored. Consequently, when accreditation is solely an external force, it elicits a resistant response from institutions. ${ }^{[18]}$ A study conducted by Bezuidenhout ${ }^{[21]}$ found that external accreditation process was viewed as unstructured, subjective, and something to fear rather than something to bring changes and improvement.

Furthermore, some of the private nursing institutions offer programs that have not been approved by nursing ETQA and students end up with qualifications that are not recognised and therefore are not permitted to work as nurses. It is further reported that some private nursing institutions employ underqualified staff to teach students. In some cases, recruitment of students exceeds the total number of students allowed per group intake, and fly-by-night private nursing education institutions charge students exuberant fees per program.

While the above studies have raised many questions on the accreditation process, these questions have remained unanswered. Hence, the current study sought to explore the perceptions of heads of private nursing education institutions on the accreditation process by the Nursing Education and Training Quality Assurance Body (ETQA) will address some of the questions on the accreditation process as accreditation is used interchangeably with quality assurance. ${ }^{[18]}$

\subsection{Aim}

The aim of this paper is to explore the perceptions of heads of private nursing institutions on benefits of School Accreditation by Nursing ETQA in the KwaZulu-Natal region, South Africa.

\section{Methodology}

An exploratory, descriptive qualitative approach was used in this study to explore the benefits of accreditation by nursing ETQA in private nursing education institutions at EThekwini District in KwaZulu- Natal South Africa. Seven heads of private nursing education institutions were purposively selected. In-depth interviews were done with each of the heads of the private nursing education institutions and the interviews took

Published by Sciedu Press between 45 minutes to an hour. Written permission to conduct interviews were obtained from the participants. Each participating head was phoned a day before to confirm the time and duration of the interview.

The instruments used for data collection were an interview guide, which was comprised of open-ended questions to be used as cues for individual interviews and field notes. The cues for interviews allowed a purposeful conversation to take place, especially in this exploratory study. ${ }^{[22]}$ The researcher made use of open-ended questions during interviews to allow diverse responses to emerging from the participants. The interview sessions were open and promoted open sharing from the participants regarding the phenomenon. Probing questions were used to guide the interview in cases where further clarification was needed.

The interviews were tape-recorded and transcribed verbatim. Data were analysed using content analysis to identify themes and sub-themes. The data were coded by the researcher and co-coded by the independent coder. The inconsistencies between the researcher and independent coder were discussed, and the consensus was researched for unambiguous themes and subthemes. Ethical principles were respected throughout the study, and ethical clearance was secured from the University of Kwa Zulu-Natal. Permissions were also obtained from the nursing education institutions where the study was conducted.

\section{FINDINGS}

The study findings indicated that there are challenges and benefits associated with the accreditation of the institution by ETQA.

\subsection{Benefits of accreditation}

In this study, the perceived benefits of Institutional Accreditation by Nursing ETQA were grouped into four themes (a) institutional benefits, (b) nurse educators' benefits (c) students' benefits and (d) nursing education benefits.

\subsubsection{Institutional benefits}

Participants explained that the feedback and reports provided by the ETQA after the accreditation process benefit the institutions. They also explained that the opinions of nursing experts and authoritative reports force rectification of identified deficiencies. Some participants mentioned that accreditation enables the institution to reflect and identify its strengths and weaknesses and decide on areas for change. This was indicated in the following quotes from some of the participants:

"We benefit a lot from the accreditation process report because opinions from experts force us 
to rectify the gaps and deficiencies. Strengths and weaknesses are identified, and changes are effected as soon as possible because the council puts down time frames for rectification" (Transcript 1).

"Accreditation helps us to reflect and identify areas of strengths and weaknesses and the institution has to fix what needed to be fixed and changed. We respect the authority's comments and reports because the institution uses them to correct things" (Transcript 7).

"The institution uses all reports and feedback from the South African Nursing Council's authorities to fix up the gaps identified, and this is seen as benefiting the institutions in terms of quality teaching and learning. We are able to make sure the necessary changes are done" (Transcript 3).

Participants further explained that after the accreditation process, institutions devise strategies to ensure that identified strengths are maintained and problems are addressed as these are monitored and audited periodically by the South African Nursing Council. It became evident that these strategies promote internal quality culture. Participants mentioned that once an institution has been accredited, it is looked up to as an example of best practice and networking opportunities. Furthermore, it was revealed that accreditation creates a positive image of credibility for an institutional program, as evidenced by some of the following excerpts from the participants:

"After accreditation, we had to put strategies in place to address problems that are noted by the South African Nursing Council because they monitor the changes time and again and these strategies enforce our internal quality. Our clients respect this college because they know that the curriculum is accredited" (Transcript 6).

"This college is well respected by students and community because of its accreditation status, and students even say good things about our institution to other students because of the quality of our teaching practice" (Transcript 5).

"Our institution is well respected because students know that all programs that are offered are accredited, and council now and then come and inspects the school. The South African Nursing Council visits help the school to maintain the quality all the time" (Transcript 2).
Participants expounded that their institutions are trusted by their customers and other stakeholders as they have the necessary license to offer nursing programs. Some participants revealed that the accreditation process ensures a whole range of resources, namely adequately qualified human resources, data systems, and infrastructure. Furthermore, it was mentioned that the public is assured that an accredited institution has clearly defined appropriate objectives, and the institution maintains conditions for the achievement of these objectives and their accomplishment. This was indicated in the following quotes from some of the participants:

"Various stakeholders, students, and the public have trusted for this institution because they know that we have a license to train nursing programs and they are aware that we have enough teachers to teach as we always fight to achieve our objectives" (Transcript 4).

"In this institution, we have every teaching aid that is needed to teach students. When the council visits us, they want to see our infrastructure, things like a library; computer laboratory and they even requested to see the teaching staff CVs" (Transcript 3).

"Ey... It was very difficult when we were developing the curriculum because we had to state our vision, mission, and objectives. Now it is always monitored that our teaching and learning is still in line with our objectives. They also check if we are getting closer to achieving them or not if not, and we need to evaluate and be able to identify the problem" (Transcript 6).

Some participants mentioned that their approved standards function as a lever for change and reform in the institution and these standards are used as the basis for evaluation and measurements of teaching and learning quality. It emerged that accreditation promotes standardisation and improves the effectiveness and quality of teaching and learning. Some participants mentioned that subject benchmarks used in developing programs are enhanced by accreditation, as indicated in the following excerpts:

"We regard our approved standards as an important tool for change and reform because they are used as the measurement for the quality of our teaching and learning; also the standardisation of procedures was enhanced, and subject benchmark improved as well" (Transcript 1).

"Hey, you know accreditation status has brought along many beneficial changes and transforma- 
tion for this institution. Procedures are standardized, and our teaching is effective now. This has also contributed positively to our subject benchmarking in the development of curriculums" (Transcript 4).

"Accreditation standards in this institution are made to monitor and evaluate the quality of our teaching and learning practice. We are also comfortable because we know that our standards of teaching and learning are the same and equal to all accredited institutions" (Transcript 3).

It also became evident that the accreditation process allowed the institutions a certain amount of flexibility to design their curricula according to the needs of the local community. This was indicated by:

"The South African Nursing Council lays down criteria to guide and direct the institution on how to develop an appropriate curriculum. The curriculum should address the needs of our local community" (Transcript 3).

"A situational analysis was conducted before we started developing our curriculum to identify the needs of our local community. The program that we offer in this institution was made to meet the needs of this community, which is the shortage of nurses in hospitals around and in the clinics. More especially, we don't have enough registered nurses, so we have developed a curriculum that is going to bridge a staff nurse to become a registered nurse" (Transcript 7).

"We also are now going to add midwifery qualification because we have that flexibility to design programs according to the needs of the local community. We have identified that the rate in teenage pregnancy is high amongst this community" (Transcript 6).

\subsubsection{Nurse educator's benefits}

Accreditation was perceived as having benefits to nurse educators in the institutions. Participants explained that accreditation clarifies the necessary standards and promotes the accountability of nurse educators to students and stakeholders. It emerged that quality does not come from the institution, but from the work of dedicated individuals in the institution, as indicated in the following:

"According to my perception, accreditation is meant to encourage nurse educators to clarify necessary standards and promote accountability

Published by Sciedu Press to students and other stakeholders. Each educator is dedicated to maintain the quality of this institution and to hold the institution's flag higher" (Transcript 2).

"Accreditation is a benefit to nurse educators because nurse educators have to clarify standards. These standards promote accountability to students and other stakeholders" (Transcript 5).

"It is not just the institution that provides quality here, but quality comes from each and every one of us. We are so dedicated to our students because we know that if they don't pass at the end of the year we will all carry the blame and the community will not trust the institution" (Transcript 6).

It also became evident that accreditation assists nurse educators to define educational guidelines, clinical guidelines and standard operating procedures to be able to assess performance compared with selected performance standards as well as take tangible steps towards improving program delivery. This was indicated as follows:

"Accreditation helps us as nurse educators to define educational guidelines, clinical guidelines as well as standard operating procedures so as to be able to assess performance and take steps to improve teaching" (Transcript 1).

"We do benefit from accreditation because as we define guidelines and standards we are able to compare our performance with selected standards and in that way improve our teaching and program delivery improves" (Transcript 3).

"Since we got accreditation, we as nurse educators are now able to use the guidelines in teaching theory as well as in practical situation. Standard operating procedures help to maintain high standards and high quality" (Transcript 6).

It became apparent that accreditation provides counsel and assistance to nurse educators and hence encourages improvement through continuous self-study. It also emerged that the South African Nursing Council encourages members of the staff in accredited institutions to further their studies and upgrade their qualifications, thus not only ensuring that the students have well-qualified teachers but also giving the staff opportunities for promotion. Participants explained that nurse educators in accredited institutions are trusted by students, parents and society in general. This was indicated in the following quotes: 
"We receive continuous assistance and support from the South African Nursing Council. They always encourage us to improve ourselves as accreditation promotes articulation and credit transfer which means there is upward mobility, and again we are trusted by the society at large" (Transcript 2).

“...Well, I can say yes, accreditation is a benefit to us because we do have support from them, they always motivate us to study further because the sky is the limit. We can even be involved in research and move up the ladder with the credits." (Transcript 4).

"Students even from outside this province do trust this institution because of the high pass rate of our students and parents who are paying the fees to have trust in the quality of this institutions teaching and learning" (Transcript $7)$.

Some of the participants revealed that accreditation has been found to be cost-effective since it promotes confidence, improves communication and fosters a clear understanding of educational practice needs and expectations. Participants further revealed that accreditation provides nurse educators with the necessary means of gauging current performance levels. Furthermore, it became apparent that accreditation promotes satisfaction and motivation in nurse educators and has proved its value in conveying the importance of maintaining a high standard of excellence to individuals who are nursing care recipients. A few excerpts from some participants are as follows:

"Accreditation is cost-effective as our confidence is promoted and we now clearly understand the needs of education and what is expected of us. We are also provided with the tool to gauge our practice. We are satisfied and motivated, and nurses from our school deliver excellent patient care" (Transcript 6).

"We have gained confidence through accreditation as we are provided with measurement tools, oh yes, we are satisfied and even more motivated. Even though the process is costly, but we think that this is a cost-effective process" (Transcript $5)$.

"We are now even able to explain to our patients how nurses trained in this institution manage to provide excellent nursing care as we always receive that positive feedback from institutions where our students are employed" (Transcript $3)$.

\subsubsection{Student benefits}

Accreditation was perceived to have benefits to students. Participants revealed that students consider accredited institutions to be examples of best practice, recognizing their programs as reliable, competent, excellent and of good quality. Participants stated further that graduates from accredited institutions are highly regarded in the workplace and sought after as it is commonly perceived that they are reliable and have received an excellent grounding in health care. Below are some excerpts:

"We have a long waiting list because students regard our programs as reliable. This institution is regarded as the best, and the programs that we are offering are accredited therefore they always say the institution is excellent and it produces quality nurses" (Transcript 3 ).

“These days' employers are keen to employ nurses that received the training from an accredited institution because they know that accredited institution offers quality programs as the institutions get scrutinised by South African Nursing Council time and again. Students are confident about the school and the programs offered" (Transcript 2).

"Hey, our graduates are the best. Hospitals have confidence in our students, and our graduates are given first preference amongst the huge number of applicants because we are regarded as offering reliable programs" (Transcript 4).

Participants explained that nurses have a vital role to play as they are constantly dealing with patients and therefore have to have the necessary skills and knowledge to carry out their duties. The quality assurance of the accreditation process ensures that the private institutions equip the nurses with these. Participants said that it was evident that feedback from the community reveals that the institutions produce quality nurses who are able to function independently, as indicated in the following excerpts:

"We all know that nurses are the ones that are next to patients all the time and even when doctors are not around. Therefore, they should have excellent skills and knowledge to provide care to patients. Therefore, quality training of nurses is paramount to avoid medico-legal hazards. Nurses from this institution are the best, 
and this is the feedback we always receive from the community" (Transcript 2).

"The community is always telling us that nurses graduated from our institution are able to work as independent practitioners because the accrediting body makes it a point that quality is maintained at high levels all the time in our institution as an accredited institution" (Transcript 5).

Participants further revealed that accreditation protects students from exploitation by private nursing institutions using false and misleading advertising and marketing material. Some participants explained that accreditation safeguards students against illegal private nursing institutions which falsely claim to offer programs leading to enrolment as nurses when, in fact, graduate students cannot be registered as nurses because the institution is not accredited by the South African Nursing Council. This is evident in the following few excerpts from participants:

"I was trying to say that students benefit from accreditation because they are safeguarded from exploitation by the illegal institution that uses fraudulent misleading advertising material. These schools claim to train nursing programs, but in the end, the students are not registered as nurses with the South African Nursing Council" (Transcript 6).

"Other illegal schools use incorrect information to recruit students. They tell students that they train nurses and they make them pay money, yet at the end of the training there are no nursing certificates and students cannot be employed as nurses without certificates from the South African Nursing Council" (Transcript 2).

Some participants explained that accreditation promotes mobility of students to higher NQF levels. It also emerged that accreditation promotes flexibility, articulation of programs and degrees by the credit transfer system and credits accumulation. Participants revealed that accreditation establishes an evidence-based education that reveals the authenticity of the students' competence, hence creating consistency and development of performance evidence, as stated in the following:

"I'm trying to explain that accreditation helps students to be able to move to higher levels and move with credits to other programs because credits accumulate and they can be transferred as long as the institution is accredited" (Transcript 5).

Published by Sciedu Press
"We see accreditation as a benefit to students because consistency is promoted, and the evidence of competency is demanded all the way as we have to account for what we have taught students, and this performance evidence leads to the authenticity of the outcome" (Transcript 7).

"I can say students benefit a lot from institutions accreditation status because they are easily employable as they are regarded as quality" (Transcript 6)

\subsubsection{Nursing education benefits}

Participant's perceived accreditation as beneficial to nursing education as the process stimulates a review of all functioning parts of the nursing education system. Some participants mentioned that accreditation creates a positive image and credibility for nursing education programs. This was indicated in the following quotes:

"Accreditation has a benefit to nursing education as a whole because the South African Nursing Council evaluates all systems in the institution, even security and safety measures" (Transcript 7).

"The positive image and credibility of the institution and its programs is created by accreditation status of the institution" (Transcript 4).

"Yes, nursing education benefits a lot from accreditation as the image and credibility of programs is promoted by accreditation" (Transcript $3)$.

"This accreditation is good because even the South African Nursing Council cannot do things anyhow because they know that there are officials above them who audit their work. Therefore, they always make it a point that all accredited institutions maintain quality teaching and learning at all times" (Transcript 6).

It emerged that accreditation fosters excellence through the development of criteria and guidelines that encourage improvement through continuous review of the system, thus assuring other faculties in education, the community and the general public that nursing education has appropriate, clearly defined objectives and maintains conditions for achievement. Furthermore, participants revealed that accreditation helps to guarantee the improvement of nursing education at different levels, as indicated by:

"Accreditation stimulates a continuous review of the guidelines and criteria, and other faculties 
are aware that nursing programs have clearly defined objectives. The institutions accomplish all its set objectives and accreditation assists to guarantee quality improvement at all levels" (Transcript 2).

"Institutions that are accredited provide excellent training because they work according to set criteria and set guidelines, and the institutions that are accredited are aware that they are being monitored at all times" (Transcript 3).

"We all know that the community and the general public is observing our institution to check if we still maintain high standards of teaching and learning at all times as they know that things are changing all the time and we need to move with times" (Transcript 1).

It became apparent that through accreditation, the on-going evaluation of existing curricula addresses problems that have been identified and ensures that the quality of nursing education in South Africa is consistent with international standards. This was indicated in the following quotes from some of the participants:

"I perceive accreditation as a benefit to the entire nursing education in South Africa because standards and accreditation components keep on evaluating the programs and help to fix the problems which result in quality teaching and learning, and nursing education competes at a global level. Accreditation brought together nursing education to become coherent" (Transcript 2).

"Oh yes, we are able to compete globally because accreditation made nursing education to be one coherent system with the same high standards and high-quality programs that can compete in the global higher education market" (Transcript 1).

It was further revealed that graduates from South African nursing education institutions are easily marketable throughout the world because of their high quality and competency. It was explained that this phenomenon is brought about by the improved and transformed nursing education system. A few excerpts from some participants are:

"We produce the high calibre of nurses that are at the world-class level because of the improvements and transformation brought by accreditation in nursing education. Graduates from South African nursing education institutions are easily marketable throughout the world" (Transcript 2).

"It is known that nurses who receive training from our accredited institutions are very good. They provide quality patient care, and this is as a result of the high standards set for accredited institutions in this country. This is brought about by the transformation in the nursing education system “(Transcript 5).

\subsection{Challenges of accreditation}

In this study, the reported challenges of accreditation included: (a) a disjoint and an inconsistent process of accreditation, (b) unclear criteria for accreditation, (c) the high cost of accreditation, (d) accreditation being detrimental to teaching the outcome, (e) lack of uniformity in the recommendations; and (f) a lengthy process of accreditation.

\subsubsection{Disjointed and inconsistent process of accreditation}

The participants revealed that the accreditation process has lots of challenges, and the process is not perfect. It emerged that although the process is geared towards creating an image which promises quality teaching and learning, the process is disjointed, not always consistent and that certain gaps, such as the lack of quality patient care outcomes, have been identified. This was indicated in the following quotes:

"No ways, accreditation has lots of challenges, and the process is not perfect at all. No matter how hard you work there will always be something wrong. Quality of all nursing education is assured to the public, yet no quality patient care outcomes are included, evaluation of the quality of patient care by nurses from accredited institutions must be included..." (Transcript 2).

"With accreditation, we are never commended; we are always made to feel inferior and feel that we are not perfect, whereas it is the process of accreditation that is not perfect. When you think you have mastered something, next time it is changed. Things are changing every day. I think the reason is that the process is disjointed" (Transcript 1).

Some participants revealed that the institutions do not always implement the recommendations of the accreditation committee right away and become complacent in the knowledge that the next scheduled visit would be in five or seven years. It also emerged that some objectives accepted by the accreditation committee are impractical. A few excerpts from some participants are as follows:

ISSN 1925-4040 E-ISSN 1925-4059 
"There is a lot of work to be done after the accreditation visit. Sometimes we don't even get time to look at recommendations and compliments due to the high volume of work. One has to touch it when they visit the institution after five or seven years." (Transcript 4).

"No one makes follow up to check if suggestions made were implemented" (Transcript 1).

"I can say sometimes objectives set and accepted by accreditation committee are not practically doable and you find that after accreditation we are unable to implement them exactly the way they are stipulated and you continue to do things the way you have been doing it because there is no guidance" (Transcript 6)

\subsubsection{Unclear criteria for accreditation}

It emerged that certain criteria of the accreditation committee are sometimes unclear. Some participants revealed that the peer review system causes a conflict of interest amongst the staff. It also emerged that accreditation checks on the quality of the assembly line instead of checking on the quality of production outcomes, which are the students' achievements. This was indicated in the following quotes:

"Other things like criteria set by the accreditation committee are not clear. There is a conflict of interest amongst the staff due to the peer review system as needed to enhance quality. Accreditation criteria only focus on the way things are done instead of checking quality in student's performances and student's achievements." (Transcript 7).

"Accreditation sometimes creates unnecessary competition amongst the staff within the same institution which at some stage causes unhealthy attitudes amongst the staff, and this affects the teaching and learning" (Transcript 5).

\subsubsection{The cost of accreditation is high}

Furthermore, it was revealed that the accreditation process is costly in terms of finance, time and human resources. Participants explained that the number of students is limited per cohort of students and that the institution should have insurance for each student, the rents are high, and private nursing institutions are expected to pay for airline tickets, transport to and from airport, accommodation, and refreshments for nursing council evaluators. Participants complained that extra staff was needed to deal with the accreditation process and that much time is spent on preparations for accreditation visits, as stated in the following abstracts:

Published by Sciedu Press
"Accreditation is costly because the institution pays for the flight, pays for transport from the airport to school, and pays for accommodation and food for nursing council evaluators. We have to employ more staff so that some focus on teaching and some to prepare for accreditation" (Transcript 3).

"This process is costing the institution a lot of money since we have to transport these people from the airport, from the airport to the school and pay for their accommodation and provide them with food a lot of money was spent on employing additional staff" (Transcript 1).

"We are forced by law to take insurance for each student that is in the institution, and this procedure is taking a lot of money because you cannot use that money for anything" (Transcript 6).

"We have a limited number of students to take per group a lot of money is used to pay the rent because we don't own the building, and yet we still have to pay for this expensive process" (Transcript 3).

\subsubsection{Accreditation being detrimental to teaching the out- come}

In this, study participants revealed that accrediting bodies do not offer help when it is needed, and the whole process of accreditation interrupts teaching and learning, which are the key focus of the institution:

“Accreditation doesn't offer help when help is needed. These people are biased, and they have favouritism. This process is so disturbing it makes us neglect our students and concentrate on paperwork which at the end will not make student pass" (Transcript 5).

"The whole procedure interrupts teaching and learning which the key focus of the institution. The process involves a lot of paperwork that needs your whole attention. I do not know, but other people are not treated like we are treated. Sometimes we appear as if we are not professional nurses; we like we don't know what we are doing "(Transcript 7).

\subsubsection{Lack of uniformity in the recommendations}

Participants explained that the provided recommendations lack the uniformity. It was reported that although different institutions might be accredited at the same time, using the same criteria, the credits transfer, credits accumulation, articulation and progression is not practicable as accredited 
nursing education institutions are in competition with each other, and there is very little continuity in the process, as stated in the following abstracts:

"I really do not know why the accreditation process is not smooth. Sometimes they say they want this, next time they are changed, it is not what they want last time. In principle, they talk about transferring of credits, but this has never happened even if the student has trained in an accredited institution" (Transcript 3).

"It is not easy for our students to transfer or upgrade themselves in other colleges because colleges are competing with one another. Other institutions think they better than others, and this takes place on the expense of students" (Transcript 4).

"The accreditation process is not consistent, and it is not continuous. I hate it" (Transcript 2)

\subsubsection{A lengthy process of accreditation}

It became apparent that accreditation is a lengthy process that can take up to three years to be completed. Participants revealed that documents sometimes disappear along the way and that this delays the process. A few excerpts from some participants are as follows:

"This is a very lengthy process. It can even take three years. Sometimes they lose our documents, and you have to send them again, for me, this is the main cause of the delay" (Transcript 3 ).

"We don't like this accreditation at all because it takes a year before you can know whether the institution is going to be given the license to train nurses or not" (Transcript 5).

"I really don't understand why the whole process is so slow; it took us almost three years to get accreditation after the initial visit. One document can be requested more than two times even if you tell them that the document was submitted" (Transcript 6).

\section{Discussion}

Accreditation has made a significant impact in regulating, improving and maintaining quality assurance in nursing education. Over the past years, nursing education in South Africa was increasingly under pressure to produce nurses who are capable of working in a changing environment influenced by social and political change, change in disease profile and technological advancement. It was revealed from the findings in this study that private nursing education institutions in EThekwini District KwaZulu-Natal responded positively to this call by SAQA to accredit private nursing education institutions and the programs offered.

The findings from this study indicated that accreditation afforded an opportunity for continuous improvement of the institutions and educational programs. As stated by ANCC, ${ }^{[10]}$ the accredited program is committed to ensuring the integrity of the accreditation process through systemic, evidencebased evaluation of application materials submitted. The results from this study indicated that there are defined standards for high performances and measures of these for highquality provision.

According to Commission of Sport Management Accreditation $^{[23]}$ accreditation protects the interest of students, parents, the academic institutions themselves and potential employers by ensuring that the educational programs offered have attained a level that meets or exceeds standards that were developed by experts in the field. While accreditation does not ensure that every graduating student will become a successful professional, but it does guarantee that the student has demonstrated a certain set of skills and abilities that are reflected in the accreditation criteria. ${ }^{[23]}$

The results from this study revealed that accreditation provides educational programs with opportunities for selfdefinition and self-reflection and with feedback on program content and direction. SANC ${ }^{[24]}$ stated that nursing institutions applying for accreditation should conduct a selfassessment which is a comprehensive and systematic review, and the results referenced the required nursing council prescribed accreditation requirements, criteria, and standards for nursing education and training. This type of assessment allows the institution to discern their strengths and areas in which improvement can be made to be able to develop and deliver quality education and training. ${ }^{[24]}$ Similarly, Nicklin ${ }^{[25]}$ points out that accrediting bodies periodically or cyclical assess the nursing education institution to measure performance against pre-established standards, this is done through self- assessment peer survey or onsite visits, interviews and careful study of the administrative documents. $\operatorname{Lim}^{[26]}$ is also of the opinion that nursing education institutions should submit the completed self-assessment tool and institutional portfolio to the SANC within three months of submitting the application.

The findings from this current study revealed that selfreflection was a part of the accreditation process as nursing education institutions had to reflect in order to identify strengths and weaknesses while completing the selfassessment tool. It also became evident from findings in this 
study that the institutions devised strategies to ensure that identified strengths are maintained as they are monitored and audited periodically by the SANC.

The Findings from this study indicated that accreditation serves as risk mitigation strategy and stimulation of the emergence of common organisational identity, culture trust, uniformity and practice. ${ }^{[27]}$ Furthermore, accreditation provides confidence to students and puts a stamp of approval graduates from an accredited institution. ${ }^{[28]}$

Although the accreditation of nursing institutions has numerous advantages, there are factors hindering its proper implementation such as a disjoint and an inconsistent process of accreditation, unclear criteria for accreditation, the high cost of accreditation, accreditation being detrimental to teaching the outcome, lack of uniformity in the recommendations; and a lengthy process of accreditation. It is essential that measure should be put in place to ensure that the accreditation is cost-effective, and consistency with the standards for validity. ${ }^{[29]}$ A multidisciplinary approach that involves all the stakeholders in the accreditation process and well-coordinated policy investments is crucial to overcome challenges of the nursing and midwifery institutions, particularly in developing countries. ${ }^{[3,30]}$

The limitation of this study include a small sample of the participants, and only a qualitative approach was used. Thus, the findings from this study cannot be generalised to the accreditation system of nursing education institutions in South Africa. Furthermore, the study was conducted only in private schools. Hence, the views of the participants may not reflect the accreditation of both public and private nursing schools. It is recommended that this study be expanded to public nursing schools and should include all the stakeholders involved in the accreditation process. In addition, a quantitative study should be conducted to explore the extent of challenges encountered by nursing education institutions during the accreditation process in South Africa.

\section{Conclusion}

In the current era of taking quality serious in nursing education accreditation contributes to ensuring that programs and degrees meet the highest standards of quality criteria. Through the accreditation process, the positive feedbacks, and advice from experts and authoritative reports force rectification of identified deficiencies. It is also a great opportunity for institutions to reflect and identify their strengths and weaknesses and decide on areas for change. Accreditation does not only benefit teaching institutions, but also the teaching staff, the students, and the educational system at large. Accreditation fosters quality improvement through a continuous review of the educational system. Furthermore, a well-conducted accreditation process increases the public confidence in nursing education through unambiguous and defensible criteria and guidelines that guide in enhancing the competencies which students can demonstrate upon graduation.

There should be an attempt to draw causal inferences about the direct influence of quality patient care from a nurse qualified from a private accredited nursing education institution compared to a nurse qualified from a public accredited nursing education institution. Ongoing institutional accreditation by a relevant quality assurance body is recommended. Nursing education institutions should devise strategies to ensure that identified strengths are maintained and should strive to continuous quality improvement. Considering that challenges are hindering the accreditation process such as a disjoint and an inconsistent process of accreditation, unclear criteria, lack of uniformity in the recommendations, there is a need for collaborative and well-coordinated accreditation of nursing schools nationally and globally.

\section{Conflicts of InTEREST Disclosure}

The authors declare that there is no conflict of interest.

\section{REFERENCES}

[1] Nicklin W. The Value and Impact of Health Care Accreditation: A Literature Review 2014 [cited 201727 October]. Available from: http://citeseerx.ist.psu.edu/viewdoc/summ ary?doi=10.1.1.677.8441

[2] Jones J, Saram DDD. Academic staff views of quality systems for teaching and learning: A Hong Kong case study. Quality in Higher Education. 2005; 11(1): 47-58. https://doi.org/10.1080/13 538320500074899

[3] McCarthy CF, Gross JM, Verani AR, et al. Cross-sectional description of nursing and midwifery pre-service education accreditation in
East, Central, and Southern Africa in 2013. Human Resources for Health. 2017; 15(1): 48. PMid:28738870 https ://doi.org/10.1 186/s12960-017-0224-1

[4] Mekwa J. Transformation in Nursing Education. South Africa: University of the North; 2000.

[5] Yan YH, Kung CM. The Impact of Hospital Accreditation System: Perspective of Organizational Learning. Health. 2015; 7(09): 1081 https://doi.org/10.4236/health.2015.79123

[6] Dickerson PS, Chappell K. Addressing Innovation: Changes in the American Nurses Credentialing Center Accreditation System. The Journal of Continuing Education in Nursing. 2011; 42(10): 441-5. 
https://doi.org/10.3928/00220124-20110401-02

[7] Uys L. The evaluation of one public nursing college in terms of the programme criteria of the higher education quality committee. Trends in Nursing. 2013; 2(1): 87-100. https ://doi .org/10.14804/2 $-1-38$

[8] Moore L, Lavoie A, Bourgeois G, et al. Donabedian's structureprocess-outcome quality of care model: Validation in an integrated trauma system. Journal of Trauma and Acute Care Surgery. 2015; 78(6): 1168-75. PMid:26151519 https ://doi.org/10.1097/TA .0000000000000663

[9] Shaw CD, Groene O, Botje D, et al. The effect of certification and accreditation on quality management in 4 clinical services in $73 \mathrm{Eu}$ ropean hospitals. International Journal for Quality in Health Care. 2014; 26(suppl 1): 100-7. PMid:24615598 https ://doi .org/10 .1093/intqhc/mzu023

[10] ANCC. ANCC primary accreditation application manual for providers and approvers. Silver Spring: American Nurses Credentialing Center; 2013.

[11] Zeller EL, Doutrich D, Guido GW, et al. A culture of mutual support: Discovering why new nurses stay in nursing. The Journal of Continuing Education in Nursing. 2011; 42(9): 409-14. PMid:21688760 https://doi.org/10.3928/00220124-20110615-02

[12] Teng CI, Dai YT, Lotus Shyu YI, et al. Professional commitment, patient safety, and patient-perceived care quality. Journal of Nursing Scholarship. 2009; 41(3): 301-9. PMid:19723279 https : //doi.org/10.1111/j.1547-5069.2009.01289.x

[13] Ralph N, Birks M, Chapman Y. The accreditation of nursing education in Australia. Collegian. 2015; 22(1): 3-7. PMid:26285403 https://doi.org/10.1016/j.colegn.2013.10.002

[14] Ralph N, Birks M, Cross W, et al. "Settling for less": Designing undergraduate nursing curricula in the context of national accreditation. Collegian. 2017; 24(2): 117-24. https://doi.org/10.1016/j. colegn. 2015.09.008

[15] SANC. Nursing Act, 2005: Act No. 33 of 2005. Pretoria: South Africa Nursing Council; 2005 [Cited 20191 June]. Available from: https : //www. sanc.co.za/pdf/Nursing $\% 20$ Act $\% 20200$ 5.PDF

[16] Isaacs S. The National Qualification Framework and the Standards Setting. Pretoria: South African Qualifications Authority; 2000 [Cited 20191 June]. Available from: http://saqa.org.za/do cs/pol/2003/standard_setting.pdf

[17] Coetzee M. Practising education, training and development in South African organisations. Pretoria: Juta and Company Ltd; 2007.
[18] Bell AC, Young S. Substances and sons: Understanding responses to teach education programme accreditation process. United States of America: East Lansing; 2010.

[19] Teshome T, Kobede K. Quality Assurance for enhancement of Higher Education in Ethiopia. Addis Ababa, Ethiopia: Higher Education Relevance and Quality Agency (HERQA); 2009.

[20] Thobega M. Enhancing quality of tertiary education through programme accreditation: A case of Botswana. Procedia-Social and Behavioral Sciences. 2010; 2(2): 2637-41. https ://doi .org/10 $.1016 /$ j.sbspro.2010.03.386

[21] Bezuidenhout M. Quality assurance in undergraduate medical education: a guide for accreditation reviews. South African Journal of Higher Education. 2007; 21(5): 427-40. https : //doi .org/10.4 314/sajhe.v21i5.50273

[22] Brink H, Van Der Walt C, Van Rensburg G. Fundamentals of Research Methodology for Health Care Professionals. 2nd ed. Cape Town: Juta and Company Ltd; 2006.

[23] CSMA. Why Should I Hire Graduates of an Accredited Program? 2015 [cited 20191 June]. Available from: https : //www . cosmaweb.org/hiring-graduates-fro m-accredited-programs.html

[24] SANC. Regulations Relating to the Accreditation of Institutions as Nursing Education Institutions 2013 [Cited 201919 September]. Available from: https://www.sanc.co.za/regulat/Reg-acc .htm

[25] Nicklin W. The Value and Impact of Health Care Accreditation: A Literature Review Canada: Accreditation Canada; 2013.

[26] Lim D. Quality assurance in higher education: A study of developing countries: A study of developing countries. United Kingdom: Routledge; 2018.

[27] COHSASA. The value/benefits of COHSASA accreditation 2016 [cited 20191 June]. Available from: http://cohsasa.co.za/wp -content/uploads/2019/04/the_value_of_accreditatio n_april_2016_final_combined_1.pdf

[28] Brittingham B. An uneasy partnership: Accreditation and the federal government. Change: The Magazine of Higher Learning. 2008; 40(5): 32-9. https : //doi .org/10.3200/CHNG . 40.5 . 32-39

[29] Buetow S, Wellingham J. Accreditation of general practices: challenges and lessons. BMJ Quality \& Safety. 2003; 12(2): 129-35. PMid:12679510 https://doi.org/10.1136/qhc.12.2.129

[30] McCarthy CF, Riley PL. The African Health Profession Regulatory Collaborative for Nurses and Midwives. Human Resources for Health. 2012; 10(26): 1-5. PMid:22931501 https://doi.org/10.1186/ $1478-4491-10-26$ 